\title{
Abordagem cirúrgica da efusão pleural parapneumônica e suas complicações
}

\author{
Surgical treatment of parapneumonic pleural effusion and its complications
}

\author{
José Carlos Fraga ${ }^{1}$, Peter Kim²
}

\section{Resumo}

Objetivo: o tratamento cirúrgico do derrame parapneumônico na criança é controverso, sendo a abordagem baseada fundamentalmente na experiência pessoal e no pequeno número de casos relatados. O objetivo deste artigo é o de apresentar uma revisão bibliográfica dos principais trabalhos e experiência dos autores no tratamento cirúrgico do derrame parapneumônico na criança.

Fonte dos dados: foram utilizados dados de artigos científicos pesquisados através dos bancos de dados Medline e Lilacs.

Síntese dos dados: o derrame parapneumônico tem indicação de drenagem cirúrgica quando apresenta, à toracocentese, aspecto purulento, bactéria no Gram ou cultura, e análise bioquímica com $\mathrm{pH}$ menor que 7,0 e glicose menor que $40 \mathrm{mg} / \mathrm{dl}$. A drenagem cirúrgica depende da fase do derrame. Na fase aguda, é suficiente a drenagem torácica fechada; na fase fibrinopurulenta, é indicada toracoscopia; na fase organizada, a toracotomia é realizada em crianças com condições anestésicas, e a pleurostomia, naquelas debilitadas e com estado geral comprometido. A ecografia é útil, e, na maioria das vezes, fundamental, para definir a fase do derrame pleural.

Conclusões: o tratamento cirúrgico do derrame parapneumônico complicado deve ser feito o mais precocemente possível, e o tipo de procedimento a ser realizado depende da fase do derrame pleural. Nas crianças que necessitam de drenagem cirúrgica, a ecografia é fundamental, para determinar a fase evolutiva do derrame parapneumônico.

J Pediatr (Rio J) 2002; 78 (Supl.2): S161-S170: derrame pleural, drenagem postural, cirurgia.

\begin{abstract}
Objective: surgical treatment of parapneumonic pleural effusion in children is controversial. The type of intervention is based mainly on personal experience and on the small number of reported cases. This article aims at presenting a literature review and the authors' experience in the surgical management of parapneumonic pleural effusion in children.
\end{abstract}

Sources: data were searched in the Medline and Lilacs databases.

Summary of the findings: complicated parapneumonic effusion should be surgically drained if thoracentesis reveals the presence of pus, positive Gram stain or culture, or $\mathrm{pH}$ less than 7.0 or glucose less than $40 \mathrm{mg} / \mathrm{dl}$. The surgical drainage depends on the stage of parapneumonic pleural effusion: at the acute stage closed thoracostomy drainage is enough; at the fibrinopurulent stage thoracoscopy is indicated; at organizational stage thoracotomy can be performed in children with stable anesthetic conditions, and open thoracostomy drainage should be used in patients in a poor state of health. Echography is very important to evaluate the staging of parapneumonic effusion.

Conclusions: surgical treatment of complicated parapneumonic effusion should be done as early as possible, and the kind of procedure depends on the stage of pleural effusion. In children with complicated parapneumonic effusion echography is very important to evaluate the staging of parapneumonic effusion.

JPediatr(Rio J) 2002; 78 (Supl.2): S161-S170: pleural effusion, surgical drainage, surgery.

\section{Introdução}

$\mathrm{O}$ derrame pleural ocorre freqüentemente em crianças com pneumonia, com incidência variando de 21 a $91 \%{ }^{1}$. A análise macroscópica, bioquímica e bacteriológica deste líquido pleural parapneumônico avalia a necessidade da drenagem cirúrgica. 
O tratamento cirúrgico do derrame parapneumônico complicado na criança é controverso, e tem sido baseado na experiência pessoal e no limitado número de casos relatados na literatura ${ }^{2}$. As decisões cirúrgicas são influenciadas por uma série de variáveis, tais como idade e estado clínico do paciente, resposta à antibioticoterapia, microrganismos na cultura e estágio e duração do empiema ${ }^{2}$. Os tratamentos possíveis incluem somente antibióticos, ou antibióticos associados à toracocentese ${ }^{3}$, drenagem torácica fechada ${ }^{4}$, fibrinolíticos ${ }^{5}$, toracoscopia ${ }^{6-8}$, minitoracotomia ${ }^{9,10}$, drenagem torácica aberta ${ }^{3}$ ou toracotomia usual ${ }^{11,12}$.

Apesar de não haver consenso, o manejo do derrame parapneumônico complicado deve ser realizado de maneira organizada e sistemática, a fim de determinar a indicação e o tipo de drenagem cirúrgica, que deve ser realizada o mais precocemente possível. Isso possibilita uma abordagem mais racional, com redução de custos do tratamento e possibilidade de análise e comparação futura dos resulta$\operatorname{dos}^{13}$.

\section{Definição}

O derrame pleural associado à pneumonia é denominado derrame parapneumônico. Esse derrame é classificado como complicado e não complicado ${ }^{14}$.

O derrame parapneumônico não complicado é um exsudato reacional à infecção pulmonar adjacente e, em geral, é reabsorvido com o tratamento antibiótico e a cura da infecção pulmonar. Ele é um derrame não purulento, sem germens no exame direto (Gram) ou na cultura, com análise bioquímica mostrando $\mathrm{pH}$ maior que 7,2, glicose maior que $40 \mathrm{mg} / \mathrm{dl}$ e desidrogenase láctica (LDH) menor do que $1.000 \mathrm{UI} / \mathrm{l}^{14}$.

Oderrame parapneumônico complicado é purulento, ou apresenta gérmen na cultura ou no Gram, ou a análise bioquímica mostra pH menor que 7,0, glicose menor do que $40 \mathrm{mg} / \mathrm{dl}$ e $\mathrm{LDH}$ maior do que $1.000 \mathrm{UI} / \mathrm{l}^{14}$. O empiema, definido como o acúmulo de pus intrapleural, é o típico derrame parapneumônico complicado.

Independentemente da presença ou não de pus ou gérmen no líquido, o derrame complicado deve ser manejado como empiema, já que há uma grande tendência à loculação e, se não tratado adequadamente, evolui para a supuração franca. A detecção do derrame parapneumônico complicado carrea aumento significativo da morbidade e mortalida$\mathrm{de}^{8}$, e sua presença sempre requer drenagem cirúrgica ${ }^{14}$.

\section{Fisiopatologia}

Como inicialmente definido, pela Sociedade Torácica Americana, em 1962, a evolução do derrame pleural parapneumônico exibe três fases bem distintas ${ }^{15}$. Se ele for inadequadamente tratado, pode progredir através de todas as fases ${ }^{14}$. A primeira, denominada de fase aguda ou exsudativa (tão curta quanto 48 horas), é caracterizada pela rápida efusão de fluido estéril para o espaço pleural. A origem deste líquido ainda não é bem estabelecida, mas ele provavelmente origina-se do espaço intersticial do pulmão ${ }^{14}$. Este líquido, neste estágio, caracteristicamente tem pequena quantidade de leucócitos e LDH, bem como níveis normais de $\mathrm{pH}$ e de glicose ${ }^{16}$, pode ser facilmente drenado, e o pulmão reexpande rapidamente.

Se o tratamento antibiótico não for adequado, em algum momento, as bactérias do processo pneumônico contíguo invadem o espaço pleural, iniciando a segunda fase, denominada de fase fibrinopurulenta (de 2 a 10 dias do início do processo). Este estágio é caracterizado pelo acúmulo de grande quantidade de líquido pleural, com muitos leucócitos polimorfonucleares, bactérias e restos celulares. A fibrina é a seguir formada e depositada sobre ambas as pleuras, visceral e parietal, havendo uma tendência à formação de septos, com loculação do derrame. A loculação previne a disseminação do empiema, mas torna difícil a remoção do líquido da cavidade pleural. À medida que este estágio progride, o líquido pleural tende a apresentar baixos níveis de $\mathrm{pH}$ e de glicose e elevados valores de $\mathrm{LDH}^{14}$. Para ocorrer reexpansão do pulmão, é necessário ruptura dos septos e remoção de toda a fibrina.

A última fase, denominada de fase organizada (2 a 4 semanas após infecção primária), é caracterizada pela presença de fibroblastos nas superfícies de ambas as pleuras, visceral e parietal, que originam uma membrana espessa e inelástica, que cobre o pulmão e reduz sua expansibilidade. Mesmo após a remoção de todo o líquido e da fibrina da cavidade pleural, não ocorre a expansão completa do pulmão. Neste estágio, o líquido pleural é espesso, e se o paciente não for adequadamente tratado, o fluído pode drenar espontaneamente para o pulmão, produzindo uma fístula broncopleural ${ }^{14}$.

\section{Diagnóstico}

A apresentação clínica do derrame parapneumônico é indistinguível da pneumonia subjacente, e, geralmente, ambas se manifestam por febre, taquicardia, taquipnéia, dispnéia e tosse produtiva. Crianças maiores podem se queixar de dor torácica pleurítica. Exame clínico mostra redução do murmúrio vesicular e macicez à percussão do hemitórax envolvido.

O diagnóstico é feito freqüentemente por radiografia de tórax, obtida em posições ântero-posterior e perfil. O líquido pleural pode ocupar todo hemitórax, com desvio do mediastino e da traquéia para o lado contralateral. A ecografia é o melhor exame para diagnóstico de líquido pleural $\mathrm{e}$, principalmente, da presença e quantidade de fibrina neste líquido, determinando o estágio do derrame ${ }^{17}$. A tomografia computadorizada é mais utilizada para avaliar complicações do derrame parapneumônico, tais como extensão da pneumonia, necrose pulmonar, pneumatoceles, abscesso 
pulmonar, fístula broncopleural, bem como excluir outras doenças, como abscessos subdiafragmáticos e derrames originados de tumores do pulmão, da parede torácica, do mediastino ou do fígado ${ }^{17}$.

A identificação do tipo de líquido pleural parapneumônico somente é possível através da realização de toracocentese diagnóstica. O procedimento também é útil para isolar e identificar o gérmen causador da infecção. A toracocentese deve ser realizada idealmente antes do início dos antibióticos, especialmente se houver, em radiografia torácica em decúbito lateral, derrame pleural maior do que $1 \mathrm{~cm}$ entre o pulmão e a parede torácica ${ }^{14}$. O líquido deve ser avaliado quanto ao aspecto e a cor, e a seguir, encaminhado para exame bacteriológico e bioquímico. Alguns testes utilizados para detecção rápida de antígenos no líquido pleural, como é o caso da aglutinação de partículas de látex, têm sido utilizados para identificação de antígenos capsulares de pneumococos e de Haemophilus influenzae tipo $\mathrm{b}^{18}$. Isso possibilita a detecção precoce do agente causal do processo pneumônico.

\section{Tratamento}

Recentes estudos têm enfatizado a importância do tratamento precoce e agressivo do derrame parapneumônico complicado. Embora o manejo permaneça controverso, é importante, além do uso de antibióticos parenterais adequados, que este derrame seja tratado o mais precocemente possível e de acordo com o estágio de evolução da doença 8,19

A drenagem cirúrgica do empiema é baseada fundamentalmente no exame do líquido pleural (Figura 1), sendo indicativo de drenagem a presença de líquido purulento, gérmen na cultura ou no Gram e análise bioquímica, com pH menor que 7,0, ou glicose menor que $40 \mathrm{mg} / \mathrm{dl}$. Crianças que apresentam líquido pleural parapneumônico com $\mathrm{pH}$ entre 7,0 e 7,2, ou LDH maior que $1.000 \mathrm{UI} / \mathrm{ml}$, devem ser consideradas individualmente ${ }^{14}$. Na presença de um derrame volumoso, com a criança apresentando-se febril e em mal estado, a drenagem deve ser instituída; na criança estável, com pequeno derrame, pode ser útil uma nova toracocentese, após intervalo de 12 a 24 h (Figura 1).

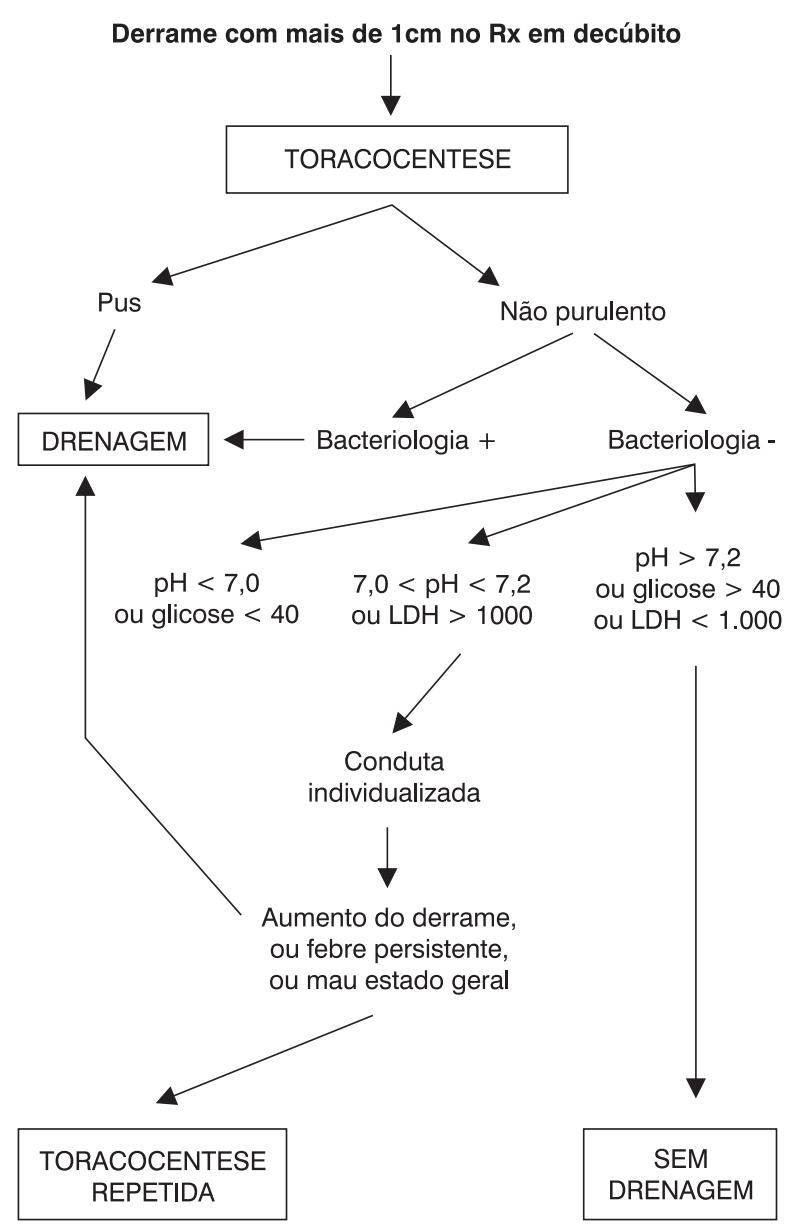

Figura 1 - Manejo do empiema ${ }^{13}$ 
A presença de derrame pleural septado não é por si só indicação de drenagem cirúrgica ${ }^{14,20,21}$. É importante a análise do líquido pleural, já que as loculações podem indicar apenas intensa resposta inflamatória no espaço pleural, sem haver necessariamente complicação do líquido através da presença de bactéria, ou de valores baixos de $\mathrm{pH}$ ou de glicose. Entretanto, a maioria das crianças com derrame pleural loculado apresenta alguma anormalidade no líquido pleural, indicativa de drenagem ${ }^{14,21}$.

O manejo do derrame parapneumônico complicado tem sido baseado no conhecimento da história natural do derrame, sendo que o tipo de drenagem cirúrgica depende do estágio do mesmo (Figura 2).

Na fase aguda, a colocação de um dreno torácico calibroso na porção mais inferior do derrame é geralmente suficiente para retirar todo o líquido pleural e permitir a reexpansão do pulmão ${ }^{14}$.

Em derrames complicados, na fase fibrinopurulenta, é importante remover a fibrina e romper as septações pleurais, a fim de permitir reexpansão completa do pulmão (Figura 2). O material fibrinopurulento não é totalmente removido através da drenagem torácica (mesmo quando se utilizam drenos calibrosos), devido ao espessamento do líquido e das septações que tornam o derrame loculado.
Nessa fase, torna-se necessário a realização de toracoscopia (Figura 2).

Em derrame na fase organizada, em que o pulmão não consegue expandir, mesmo após a remoção do líquido pleural, o tratamento definitivo pode ser realizado por toracotomia e limpeza de todo o material pleural, quando a criança tem condições clínicas de resistir a uma cirurgia de grande porte, ou por pleurostomia, naqueles pacientes debilitados e com alto risco anestésico. Esses procedimentos têm sido usados cada vez com menos frequiência em crianças, pois, na maioria dos casos, se realiza intervenção cirúrgica nas fases aguda e fibrinopurulenta do derrame ${ }^{20}$.

\section{Tipos de drenagem pleural}

A remoção do líquido pleural permanece como procedimento fundamental no tratamento do derrame parapneumônico complicado. A retirada do líquido pleural permite a expansão do pulmão e o contato entre as pleuras, com conseqüente obliteração do espaço pleural e cura da infecção.

A drenagem pleural pode ser realizada por drenagem tubular fechada, toracotomia ou toracoscopia. A indicação do momento ideal de realização de cada uma delas foi discutida previamente.

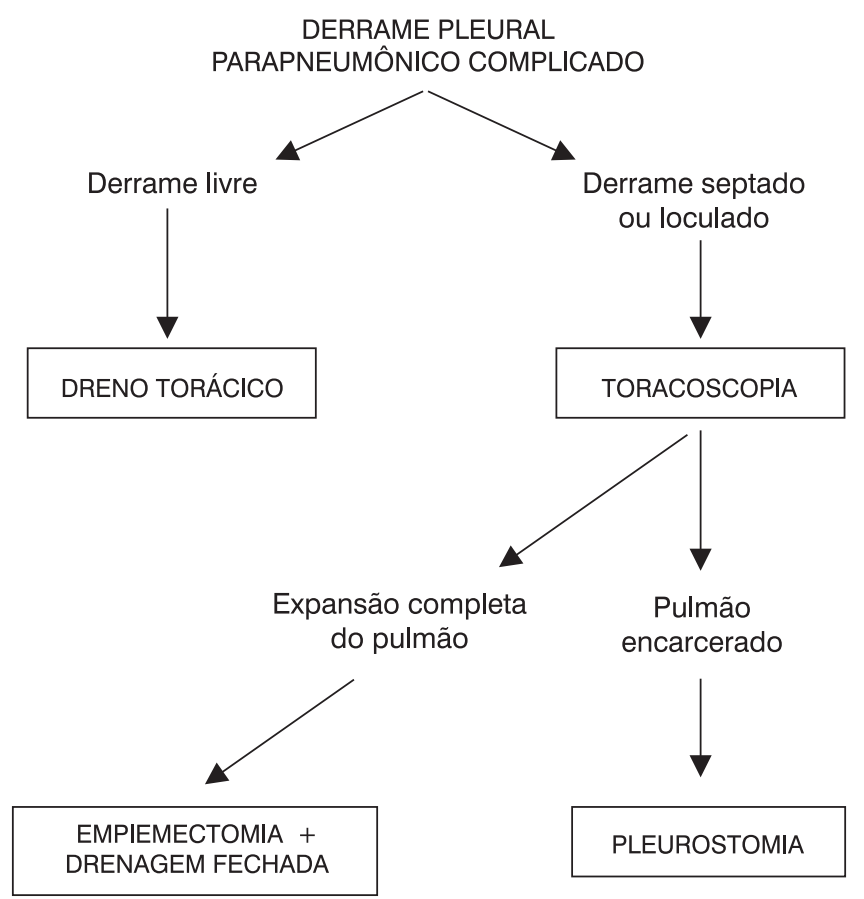

Figura 2 - Tipos de drenagem no empiema 


\section{Drenagem tubular fechada}

Para a drenagem torácica de derrame parapneumônico prefere-se a utilização de drenos tubulares de silicone, com vários orifícios laterais. Eles são firmes, mas maleáveis, baratos e provocam mínima reação da pele ou da pleura. Deve-se usar o dreno mais calibroso possível, pois eles têm menor propensão à obstrução.

A drenagem pleural fechada de líquido é realizada na porção mais inferior da coleção líquida, na linha axilar posterior. Nos derrames sem septação, as porções mais inferiores geralmente correspondem ao $5^{\circ}$ ou $6^{\circ}$ espaços intercostais. $\mathrm{O}$ ideal é verificar a região mais inferior do derrame através de toracocentese, realizada imediatamente antes da inserção do dreno. Deve-se evitar a colocação de dreno abaixo do $6^{\circ}$ ou $7^{\circ}$ espaços intercostais, devido ao risco de lesão do diafragma ou de vísceras abdominais. $\mathrm{O}$ dreno deve preferentemente ser deixado em selo d'água, sem aspiração.

Para a inserção do dreno torácico, é importante sedação da criança, se as condições clínicas permitirem, com midazolan ou hidrato de cloral, e adequada imobilização através de contensão (técnica de "mumificação"). Anestesia geral pode ser utilizada em crianças que apresentem condições anestésicas. A criança é colocada em decúbito dorsal, com braço e antebraço homolateral elevados, a fim de alargar os espaços intercostais. Pequeno coxim é colocado sob o hemitórax a ser drenado. Faz-se anti-sepsia do hemitórax com iodofor aquoso, e anestesia da pele, tecido subcutâneo e pleura parietal no local de colocação do dreno com lidocaína. A punção dos espaços intercostais inferiores confirma o correto local da drenagem torácica. Após ser estabelecido o local da colocação do dreno, realiza-se incisão de pele com bisturi, do tamanho do dreno a ser inserido. Incisões grandes podem provocar escape de ar, com conseqüente enfisema subcutâneo. A seguir, divulgese o subcutâneo e a musculatura intercostal com pinça hemostática, até ocorrer penetração da cavidade pleural. É importante que a dissecção seja realizada junto à borda superior da costela inferior do espaço intercostal, para evitar lesão dos vasos intercostais. Não se deve seccionar a musculatura, pelo risco de sangramento. $\mathrm{O}$ dreno é então introduzido no espaço pleural, acoplado à pinça utilizada previamente para abrir o orifício de drenagem, conectado ao sistema de drenagem e fixado à pele com fio nãoabsorvível. O ponto de fixação é colocado em forma de "U", e amarrado de maneira que possa ser utilizado para fechar o orifício de drenagem no momento da retirada do dreno. Antes da fixação do dreno, deve-se ter cuidado de não deixar nenhum orifício do mesmo para fora da cavidade torácica. Realiza-se então curativo com gaze e micropore.

Radiografia de tórax (ântero-posterior e perfil) deve ser realizada logo após a drenagem torácica, a fim de avaliar a posição do tubo e a reexpansão pulmonar. Cuidadosa monitorização diária da natureza e volume da drenagem deve ser realizada até que o tubo seja removido.
O dreno torácico deve ser removido quando a drenagem líquida for mínima e quando não houver escape de ar. O clampeamento do dreno antes da remoção é bastante discutível, e não é realizado rotineiramente por nós. Durante a retirada do dreno, é fundamental o fechamento rápido do seu orifício de inserção na pele, para evitar a entrada de ar para a cavidade pleural. Radiografia torácica deve ser realizada 6 a 12 horas após a remoção do dreno, para confirmar a expansão completa do pulmão.

\section{Toracotomia}

A drenagem pleural do líquido parapneumônico complicado pode ser feita por toracotomia, que é útil para drenagem do líquido pleural, ruptura das aderências e remoção da fibrina, bem como, quando necessário, ressecção de tecido pulmonar necrótico, ou que apresente fístula broncopleural ${ }^{22,23}$. Esse procedimento cirúrgico foi erradamente denominado, no passado, de decorticação ou decorticação precoce. Esse termo não deve ser utilizado, já que, na realidade, não se realiza uma verdadeira decorticação, com remoção de pleura, mas sim a limpeza de todo o conteúdo intrapleural, cuja melhor denominação seria "empiemectomia" (Figura 2).

A toracotomia era preconizada em derrames na fase fibrinopurulenta ou organizada ${ }^{23}$, e poderia ser realizada através de incisão póstero-lateral clássica ${ }^{23}$, ou por minitoracotomia ${ }^{9,10}$. Devido às complicações associadas ao procedimento, especialmente deformidade da parede torácica, perda sangǘnea significativa e maior probabilidade de ressecção de parênquima pulmonar e de fístula broncopleural, ou pneumonia pós-operatória, ele é realizado atualmente somente em casos de derrame complicado, em estágio organizado. Importante considerar que, diferente do paciente adulto, o espessamento pleural observado em derrame parapneumônico complicado em crianças tem um curso benigno, resolvendo espontaneamente, sem necessidade de intervenção cirúrgica ${ }^{24}$.

Com a crescente utilização da videocirurgia pediátrica, a toracoscopia tornou-se o procedimento ideal para crianças com derrame complicado em estágio fibrinopurulento, apresentando inúmeras vantagens em relação a toracotomia, como: menos dor pós-operatória e retorno mais precoce às atividades; reduz a ansiedade dos pais no cuidado pósoperatório e o tempo de internação das crianças; reduz a possibilidade de ressecção de parênquima pulmonar e a necessidade de transfusão sangüínea; evita toracotomia e suas sequielas, com ótimo resultado estético; encoraja pediatras a encaminharem pacientes com derrame complicado precocemente para avaliação cirúrgica ${ }^{25}$.

A pleurostomia tem sido utilizada em crianças com derrame complicado na fase organizada, que se apresentam em mal estado, debilitadas, em que uma anestesia ou cirurgia de grande porte carrea alto risco. Este procedimento somente deve ser realizado após certificação de que o pulmão está aderido e encarcerado, sem risco de colapso 
após a abertura da cavidade pleural. Através de incisão torácica realizada na porção mais inferior da cavidade líquida, pequena porção de costela é ressecada, mantendose o periósteo. A seguir, a pele e o subcutâneo são liberados da borda da abertura torácica, de tal maneira que a pele possa ser suturada na pleura parietal. Esta abertura possibilita a drenagem das secreções, lavagem da cavidade e gradativa reexpansão pulmonar. Outra vantagem deste método é a possibilidade de alta hospitalar precoce. Entretanto, é importante que a abertura pleural esteja situada na porção mais inferior da cavidade líquida, para evitar acúmulo de secreção intratorácica abaixo do nível da pleurostomia.

\section{Toracoscopia}

A toracoscopia tem sido usada em adultos com empiema, com bons resultados. Em crianças, Kehr e Rodgers ${ }^{6}$ foram os primeiros a descrever o sucesso da toracoscopia no tratamento de empiema. Eles enfatizaram que a toracoscopia é um procedimento minimamente invasivo, que permite a lavagem e remoção da fibrina da cavidade pleural, bem como a colocação de um dreno torácico bem posicionado sob visão direta e que, quando utilizada precocemente, reduz a necessidade de outros procedimentos cirúrgicos.

A toracoscopia pode ser realizada com ou sem equipamento de vídeo. Apesar da toracoscopia videoassistida possibilitar melhor visualização da cavidade pleural, a pleuroscopia com pequeno mediastinoscópio possibilita adequada limpeza e aspiração de todo o material pleural, também propiciando expansão completa do pulmão ${ }^{26}$. Comparação da utilização de toracoscopia videoassistida ou pleuroscopia com mediastinoscópio, em crianças com derrame parapneumônico complicado, não mostrou diferença estatisticamente significante quanto ao tempo de realização do procedimento, tempo de drenagem torácica pós-operatória e tempo de internação ${ }^{20}$.

A toracoscopia é especialmente indicada no derrame parapneumônico na fase fibrinopurulenta (Figura 2), já que possibilita a ruptura das aderências e a remoção da fibrina e material infectado, com liberação de todas as superfícies pulmonares, incluindo as diafragmáticas, permitindo a reexpansão completa do pulmão e a melhora da infecção ${ }^{6}$. A toracoscopia também tem sido indicada em crianças com empiema, nas quais a drenagem com dreno tubular fechado não foi suficiente para remoção de todo o líquido pleural ${ }^{27}$. Klena et al. ${ }^{19}$ sugerem que o procedimento seja indicado precocemente em derrames septados, após a drenagem torácica, em crianças que permaneçam doentes. Merry et al. ${ }^{28}$, em revisão de 23 crianças com empiema submetidas à toracoscopia, relatam que, em 19 destas crianças, a toracoscopia foi indicada como procedimento inicial de drenagem. A indicação da toracoscopia foi a presença de derrame loculado, diagnosticado pela insuficiência de drenagem de todo o líquido através da toracocentese, ou através de radiografia de tórax, ecografia ou tomografia computadorizada $^{28}$. Subramaniam et al. ${ }^{25}$ recentemente compararam toracoscopia com toracotomia em crianças com empiema, e observaram que a toracoscopia reduz significativamente o tempo cirúrgico, a necessidade de ressecções pulmonares, a perda sangüínea transoperatória e a necessidade de transfusão de sangue, a necessidade de analgésicos, a duração da drenagem torácica e o tempo de internação hospitalar.

Apesar de não existir nenhum estudo randomizado e controlado em crianças que compare este método com outros, prospectivamente, também indicamos a toracoscopia como procedimento inicial de drenagem em derrames parapneumônicos complicados loculados ou septados (Figura 2).

A toracoscopia é realizada sob anestesia geral, com a criança intubada e em decúbito lateral. Quando começamos a realizar o procedimento, realizávamos intubação seletiva do pulmão contralateral; entretanto, nos últimos pacientes, foi possível a realização da toracoscopia sem necessidade de intubação seletiva. Realizamos o procedimento com 2 trocateres de $5 \mathrm{~mm}$ : o primeiro é colocado através de uma pequena incisão abaixo do mamilo. Em crianças com dreno torácico prévio, o procedimento geralmente inicia pelo orifício do dreno. Preconizamos a entrada no espaço pleural inicialmente com pinça hemostática, e então, a seguir, introduzimos o trocater. Não achamos necessidade de insuflação de $\mathrm{CO}_{2}$ pelo trocater, preconizada por alguns para favorecer o colapso pulmonar ${ }^{25,29}$. Após inspeção da cavidade com ótica de 4 ou $5 \mathrm{~mm}$, o segundo trocater é colocado na porção mais baixa do derrame pleural. Este orifício é usado posteriormente para a colocação do dreno torácico pós-operatório. Após a colocação dos trocateres, e sob visão direta, introduzem-se aspirador e pinças de dissecção, para remover o líquido e liberar todas as septações e aderências, especialmente as mediastinais e diafragmáticas, permitindo reexpansão completa do pulmão. O procedimento somente termina quando o pulmão está completamente liberado e é capaz de expandir livremente, com pressão ventilatória positiva. O dreno torácico é então colocado sob visão direta, e a pequena incisão torácica fechada com fio absorvível.

A toracoscopia para crianças com derrame parapneumônico complicado está ganhando cada vez mais adeptos. Embora a maioria dos relatos seja retrospectivo, com pequeno número de crianças, o procedimento tem-se mostrado efetivo e com mínimas complicações (Tabela 1).

Recente revisão de 29 crianças submetidas à toracoscopia para tratamento de derrame parapneumônico complicado, no Hospital de Clínicas de Porto Alegre, com faixa etária entre 8 meses a 11 anos (média de 3 anos e 3 meses), mostrou que o procedimento foi efetivo e bem tolerado ${ }^{36}$. Após a toracocentese, as crianças receberam antibioticoterapia endovenosa de amplo espectro e submeteram-se a algum tipo de drenagem. Em 23 pacientes, foi colocado dreno pleural tubular, e em 6 foi realizado toracoscopia. 
Tabela 1 - Toracoscopia no tratamento de derrame parapneumônico complicado em crianças e adolescentes

\begin{tabular}{|c|c|c|c|c|}
\hline Autor/Ano & $\begin{array}{l}\text { Número de } \\
\text { crianças }\end{array}$ & Estágio/Empiema & Eficácia* & Complicaçõos \\
\hline Kern \& Rodgers ${ }^{6} / 1993$ & 9 & II e III & $100 \%$ & Ausentes \\
\hline Stovroff $^{8} / 1995$ & 10 & II e III & $90 \%$ & Ausente \\
\hline Davidoff $30 / 1996$ & 9 & II & $78 \%$ & Não referido \\
\hline Campos $31 * * / 1997$ & 38 & II e III & $82 \%$ & Não referido \\
\hline Klena $^{19} / 1998$ & 21 & II & $71 \%$ & Não referido \\
\hline Grewal $^{32} / 1999$ & 25 & II & $96 \%$ & Hemorragia $=1$ \\
\hline Merry $^{28} / 1999$ & 19 & I e II & $100 \%$ & Ausente \\
\hline Doski $^{33} / 2000$ & 41 & I e II & $100 \%$ & Ausente \\
\hline Fraga $^{20 * *} / 2000$ & 23 & II e III & $91 \%$ & Enfisema subcutâneo $=2$ \\
\hline Rescorla 34 / 2000 & 16 & II e III & $88 \%$ & Ausente \\
\hline Subramaniam 25 / 2001 & 22 & II e III & $100 \%$ & Ausente \\
\hline Chen $^{35} / 2002$ & 19 & II e III & $100 \%$ & Ausente \\
\hline
\end{tabular}

* Eficácia - 100\% significa que não houve necessidade de cirurgia aberta.

** Utilizado mediastinoscópio e videotoracoscópio.

Nestes últimos, a toracoscopia foi o procedimento inicial devido à presença de derrame pleural com septos à ecografia. No grupo com drenagem pleural fechada, a toracoscopia foi realizada devido à presença de febre e líquido pleural residual à ecografia (com ou sem septações), com ou sem piora do estado geral, durante ou após a remoção do dreno torácico. A ecografia foi realizada antes da toracoscopia em todos os pacientes, sendo importante para determinar a presença e localização do líquido, bem como a presença de fibrina e loculações do derrame pleural. O tempo cirúrgico médio da toracoscopia foi 97 minutos (30 a $180 \mathrm{~min}$ ). A radiografia de tórax no pós-operatório imediato mostrou adequada expansão pulmonar, com espessamento pleural residual e sem evidência de derrame. Três crianças apresentaram enfisema subcutâneo na incisão cirúrgica torácica. Não foi observada infecção da incisão cirúrgica. A drenagem torácica após a toracoscopia foi em média de 7,4 dias (2 a 27). Cinco crianças necessitaram de nova toracoscopia durante o período de acompanhamento. Elas apresentaram febre e derrame pleural após a remoção do dreno torácico, e realizaram novo procedimento para remoção do líquido e fibrina. Três outras crianças, tratadas no início de nossa série, necessitaram de drenagem cirúrgica aberta. Duas delas também apresentaram derrame pleural e febre após remoção do dreno torácico, mas, devido ao encarceramento do pulmão, foi realizada pleurostomia. Uma criança apresentou drenagem através do dreno de tórax por mais de duas semanas, tendo o dreno sido cortado e aberto externamente. O tempo médio de hospitalização após a toracoscopia foi de 15,1 dias (de 5 a 26 dias). Todos os pacientes mantiveramse assintomáticos desde a alta hospitalar. Radiografia de tórax na revisão mensal mostrava espessamento pleural residual $^{36}$.

Recentes estudos têm enfatizado a importância do tratamento precoce e agressivo do derrame parapneumônico complicado. Na presença de derrame complicado loculado ou septado, sem evidência de organização, prefere-se a realização de toracoscopia ${ }^{6,28}$. Atualmente em nosso serviço, as crianças que apresentam derrame parapneumônico com indicação de drenagem fazem inicialmente ecografia torácica. Se o derrame é livre, realiza-se drenagem torácica fechada; se o derrame é loculado ou septado, realiza-se toracoscopia.

\section{Enzimas intrapleurais}

A utilização intrapleural de fibrinolíticos para degradação de derrame pleural septado e aumento da drenagem pelo dreno torácico, foi descrita, pela primeira vez, em $1950^{1}$. Problemas de reações alérgicas e neutralização do agente fibrinolítico por anticorpos durante tratamentos prolongados fizeram com que esse tipo de abordagem fosse abandonado nos anos subseqüentes ${ }^{37}$. A partir da década de 90, com a purificação da estreptoquinase e a utilização da 
uroquinase, que não produz efeitos alérgicos, novos trabalhos têm referido a utilização desse tipo de tratamento em crianças com derrame parapneumônico complicado.

$\mathrm{O}$ agente fibrinolítico degrada uma ampla variedade de proteínas, entre as quais a fibrina. A reação fibrinolítica mediada pela estreptoquinase ou uroquinase resulta da ativação do plasminogênio e formação da plasmina, que atua na lise dos septos do derrame pleural loculado, permitindo a fluidificação do material, que passa a sair da cavidade torácica pelo dreno ${ }^{38}$.

Recente estudo retrospectivo do uso de estreptoquinase ou uroquinase, em 25 crianças com empiema loculado, sugere que este método adjuvante de tratamento seja efetivo e seguro em crianças com empiema torácico ${ }^{37}$. Os autores referem que o tratamento foi efetivo em 20 deles $(80 \%)$. A indicação do uso de fibrinolíticos nesse estudo deve-se à persistência de derrame pleural parapneumônico após drenagem torácica tubular em pacientes com febre, apesar do uso de antibióticos parenterais. Cinco pacientes (20\%) apresentaram complicações, com necessidade de cirurgia. Três apresentaram fístula broncopleural, com necessidade de toracotomia, decorticação e ressecção segmentar de pulmão; dois persistiram com loculações e necessitaram toracotomia e decorticação. Nessa série, não se observaram complicações com o uso de fibrinolíticos, e o tempo médio de permanência do dreno torácico foi de 8,9 dias (variação de 8 a 17 dias). Nesse estudo não foi referido o tempo de internação das crianças ${ }^{37}$.

A grande discussão sobre o uso de fibrinolíticos como tratamento adjuvante em crianças com empiema, é que este tipo de abordagem requer prolongado tempo de internação e tem significativos índices de ineficácia ${ }^{39}$. Associado a isso, não há estudo prospectivo randomizado comparando o uso de fibrinolíticos com outros métodos de tratamento do derrame parapneumônico complicado na criança. $\mathrm{O}$ único estudo desse tipo foi realizado em adultos, e mostrou que a toracoscopia foi mais eficaz do que o uso de fibrinolítico pelo dreno torácico em pacientes com empiema, com menor tempo de internação e menor custo ${ }^{40}$. Em vista disso, e enquanto não tivermos um estudo adequado em crianças, não indicamos a utilização de fibrinolíticos em crianças com derrame parapneumônico complicado.

\section{Situações especiais}

\section{Piopneumotórax}

O pneumotórax associado ao derrame parapneumônico complicado geralmente decorre da ruptura de um microabscesso pulmonar periférico na cavidade pleural. Grande fuga aérea pode ocasionar pneumotórax hipertensivo, com dificuldade respiratória importante.

Como esse tipo de pneumotórax acompanha-se de infecção pleural, o tratamento é o mesmo do derrame parap- neumônico complicado na fase aguda, com necessidade de drenagem torácica com dreno tubular calibroso. A drenagem completa do conteúdo pleural, com expansão completa do pulmão, em geral é suficiente para o fechamento da área de vazamento no parênquima pulmonar.

\section{Fístula broncopleural}

Quando o derrame parapneumônico é complicado pela presença de uma fístula broncopleural, a realização de adequada drenagem pleural é crucial. Se isso não for realizado, pode haver drenagem de material infectado para dentro do pulmão, com piora da infecção pulmonar ${ }^{14}$.

A fístula broncopleural pode se manifestar por excessiva expectoração na criança sem doença pulmonar extensa. Radiologicamente, observa-se nível hidroaéreo intrapleural em radiografia torácica, com a criança em posição elevada. Em algumas ocasiões, é necessária a realização de tomografia computadorizada, para confirmar se o nível hidroaéreo localiza-se no espaço pleural, ou é decorrente de abscesso pulmonar.

A manifestação mais comum de fístula broncopleural é a persistência de fuga aérea após a realização da drenagem torácica fechada. O diagnóstico é confirmado após exclusão de anormalidades na vedação do dreno e intermediários do sistema de drenagem.

Como foi discutido anteriormente, empiema com fístula broncopleural associada requer drenagem torácica tubular de urgência, a fim de evitar a contaminação de todo o sistema respiratório. A criança deve, preferentemente, ser colocada em decúbito lateral, sobre o lado da fístula, a fim de prevenir a aspiração de líquido pleural para o pulmão contralateral. Para o fechamento da fístula, é fundamental que o pulmão expanda e ocupe toda a cavidade torácica. Para facilitar a expansão pulmonar, é importante reduzir a fuga de ar pela fístula, através da redução da pressão intrapulmonar e do aumento da pressão intrapleural. A primeira é obtida com a manutenção da ventilação espontânea, evitando ao máximo a intubação traqueal e a ventilação pulmonar com pressões elevadas. O aumento da pressão intrapleural é obtido através da suspensão da aspiração contínua pelo dreno torácico, que é mantido apenas em selo d'água. Com a expansão completa do pulmão, o controle da sepse, a cura da infecção pulmonar e o adequado suporte nutricional, geralmente podemos esperar fechamento da fístula brônquica em alguns dias. Caso a mesma persista além de 2 a 4 semanas, há, em geral, necessidade de fechamento cirúrgico da fístula brônquica.

A correção cirúrgica da fístula broncopleural na criança deve ser preferentemente realizada por toracotomia, já que é difícil a realização deste procedimento por videotoracoscopia $^{34}$. Em geral, o fechamento de fístula broncopleural requer remoção do tecido pulmonar adjacente ao local da fístula, com sutura de cartilagem brônquica normal e fechamento do local de escape aéreo. 


\section{Pneumatocele}

Pneumatoceles são cistos pulmonares decorrentes de infecção pulmonar, resultantes de necrose bronquiolar e alveolar localizadas. A lesão determina passagem de ar para o espaço intersticial, com formação de cisto de paredes finas contendo ar. A pneumatocele pode romper e ocasionar pneumotórax hipertensivo, fístula broncopleural e empie$\mathrm{ma}^{41}$.

As pneumatoceles são tipicamente diagnosticadas na radiografia de tórax. Tomografia computadorizada pode ser útil no diagnóstico diferencial com cisto pulmonar, hérnia diafragmática ou malformação adenomatóide cística.

A maioria das pneumatoceles não requer tratamento, visto que em geral regridem progressivamente de tamanho, à medida que a infecção pulmonar é curada. Cerca de $45 \%$ delas resolvem em 6 meses, e as restantes, dentro de 12 meses, sem complicações clínicas ou radiográficas.

Quando a pneumatocele cresce muito, com compressão das estruturas e dificuldade respiratória, ela deve ser drenada com dreno tubular. O mesmo tratamento é preconizado em crianças que apresentam ruptura da pneumatocele com desenvolvimento de pneumotórax, fístula broncopleural ou empiema. A realização de toracotomia e fechamento do local de escape aéreo é raramente necessária.

\section{Referências bibliográficas}

1. Rosen H, Nadkarni V, Theroux M, Padman R, Klein J. Intrapleural streptokinase as adjunctive treatment for persistent empyema in pediatric patients. Chest 1993;103:1190-3.

2. Chan W, Keyser-Gauvin E, Davis LT, Nguyen LT, Laberge JM. Empyema thoracic in children: a 26-year review of the Montreal Children's Hospital experience. J Pediatr Surg 1997;32(6):870-2.

3. Miller JI. Infections of the pleura. In: Shields TW. General Thoracic Surgery. Philadelphia: Lea \& Febiger; 1989.p.633-49.

4. Mangete EDO, Kombo BB, Legg-Jack TE. Thoracic empyema: a study of 56 patients. Arch Dis Child 1993;69:587-8.

5. Robinson LA, Moulton AL, Fleming WH. Intrapleural fibrinolytic treatment of multiloculated thoracic empyemas. Ann Thorac Surg 1994;57:802-14.

6. Kern JA, Rodgers BM. Thoracoscopy in the management of empyema in children. J Pediat Surg 1993;28:1128-32.

7. Silen ML, Weber TR. Thoracoscopic débridement of loculated empyema thoracic in children. Ann Thorac Surg 1995;59:1166-8.

8. Stovroff M, Teague G, Heiss KF, Parker P, Rickets RR. Thoracoscopy in the management of pediatric empyema. J Pediat Surg 1995;30:1211-5.

9. Van Way C III, Narrod J, Hopeman A. The role of early limited thoracotomy in the treatment of empyema. J Thorac Cardiov Surg 1988;96:436-9.

10. Raffensperger JC, Luck SR, Shkolnik A, Rickets RR. Minithoracotomy and chest tube insertion for children with empyema. J Thorac Cardiovasc Surg 1982;84:497-504.

11. Miller JI. Empyema thoracis. Ann Thorac Surg 1990;50:343-4.
12. Gustafson RA, Murray GF, Warden HE. Role of lung decortication in symptomatic empyema in children. Ann Thorac Surg 1990;49:940-7.

13. Finck C, Wagner C, Jackson R, Smith Sam. Empyema: Development of a critical pathway. Semin Pediat Surg 2002; 11:25-8.

14. Light RW. Parapneumonic effusions and empyema. In: Light RW. Pleural diseases. $3^{\mathrm{a}}$ ed. Baltimore: Willianms \& Wilkin; 1995.p.129-53.

15. The American Thoracic Society: Management of non-tuberculous empyema. Am Ver Respir Dis 1962;85:935-6.

16. Light RW. Management of parapneumonic effusions. Arch Intern Med 1981;141:1339-41.

17. Meier A, Smith B, Rhagavan ABS, Moss LR, Harrison M, Skarsgard E. Rational treatment of empyema in children. Arch Surg 2000;135(8):907-12.

18. Boersma WG, Lowenberg A, Holloway Y, Kuttschrutter H, Snijder JA, Koeter GH. Rapid detection of pneumococcal antigen in pleural fluid of patients with community acquired pneumonia. Thorax 1993;48:160-2.

19. Klena JW, Cameron B, Langer JC, Winthrop AL, Perez C. Timing of video-assisted thoracoscopic débridement for pediatric empyema. J Am Coll Surg 1998;187(4):404-8.

20. Fraga JC, Nunes G, Schopf L, Hinke T, Antunes CRH. Toracoscopia em crianças com derrame parapneumônico complicado. Revista HCPA 2000;20:13-20.

21. Himelmann RB, Callen PW: The prognostic value of loculations in parapneumonic pleural effusions. Chest 1986;90:852-6.

22. Foglia RP, Randolph JG. Current indications for decortication in the treatment of empyema in children. J Pediatr Surg 1987;22: 28-33.

23. Kosloske AM, Cartwright KC. The controversial role of decortication in the management of pediatric empyema. J Thorac Cardiovasc Surg 1988;96:166-70.

24. Sarihan H, Cay A, Aynaci M, Abaki A. Empyema in Children. J Cardiovasc Surg 1998;39:113-6.

25. Subramaniam R, Joseph VT, Tam GM, Goh A, Cahy OM. Experience with video-assisted thoracoscopic surgery in the management of complicated pneumonia in children. J Pediatr Surg 2001;36:316-9.

26. Fraga JC, Lima A, Schopf L, Antunes CRH. Pleuroscopia com mediastinoscópio em crianças com derrame parapneumônico complicado. J Pediatr (Rio J) 1999;75:470-6.

27. Rodgers BM. Thoracoscopy. In: Holcomb GW III. Pediatric Endoscopic Surgery. Connecticut: Appleton \& Lange; 1994. p.103-17.

28. Merry CM, Bufo AJ, Shah RS, Schropp KP, Lobe TE. early definitive intervention by thoracoscopy in pediatric empyema. J Ped Surg 1999;34:178-81.

29. Steinbrecher HA, Hajmaldin AS. Thoracoscopy for empyema in children. J Pediatr Surg 1998;33:708-10.

30. Davidoff AM, Hebra A, Kerr J, Stafford PW. Thoracoscopic management of empyema in children. J Laparosc Surgery 1996;6 Suppl 1:51-4.

31. Campos JRM, Filho LOA, Werebe EC, Minamoto H, Quim LOA, Filomeno LTB, et al. Thoracoscopy in children and adolescents. Chest 1997;111:494-7.

32. Grewal H, Jackson RJ, Wagner CW, Smith S. Early videoassisted thoracic surgery in the management of empyema. Pediatrics 1999;103(5):e63.

33. Doski JJ, Lou D, Hicks BA, Megison SM, Sanchez P, Contidor $\mathrm{M}$, et al. Management of parapneumonic collections in infants and children. J Pediatr Surg 2000;35(2):265-70. 
34. Rescorla FJ, West KW, Gingalewski CA, Engum SA, Scherer III LR, Grosfeld J. Efficacy of primary and secondary video-assisted thoracic surgery in children. J Pediatr Surg 2000;35:134-8.

35. Chen LE, Langer JC, Dillon PA, Foglia RP, Huddleston CB, Mendeloff EM, et al. Management of late-stage parapneumonic empyema. J Pediatr Surg 2002;37(3):371-4.

36. Fraga JC, Komlós M, Nunes G, Schopf L. Toracoscopia em crianças com empiema. Resumo do IV Congreso de Cirurgia Pediatrica Del Cono Sur de América (CIPESUR); 2001 Nov 710; Montevideo, Uruguai. Montevideo: CDC; 2001:75.

37. Kiliç N, Çelebi S, Gürpinar A, Hacimustafaoglu M, Konca Y, Ildirm I, et al. Management of thoracic empyema in children. Pediatr Surg Int 2002;18:21-3.

38. Jerjes-Sanchez C, Ramirez-Rivera A, Elizalde JJ, Delgado R, Cícero R, Ibarra-Perez C, et al. Intrapleural fibrinolysis with streptokinase as an adjunctive treatment in hemothorax and empyema. A multicenter trial. Chest 1996;109:1514-9.
39. Krishnan R, Amin N, Dozor AJ, Stringel G. Urokinase in the management of complicated parapneumonic effusions in children. Chest 1997;112:1579-83.

40. Wait M, Sharma S, Hohn J, Nogare AD. A randomized trial of empyema therapy. Chest 1997;111:1548-51.

41. Zuhdi MK, Bradley JS, Spear RM, Peterson BM. Fatal air embolism as a complication of staphylococcal pneumonia with pneumatoceles. Pediatr Infect Dis J 1995;14:811-2.

Endereço para correspondência:

Dr. José Carlos Fraga

Rua Ramiro Barcelos 2350, sala 600 - HCPA

CEP 90430-000 - Porto Alegre, RS

E-mail: jcfraga@brturbo.com 